\title{
Antiubiquitin antibody in localised and systemic scleroderma
}

\author{
M Fujimoto, S Sato, H Ihn, K Kikuchi, T Tamaki, K Tamaki, K Takehara
}

\begin{abstract}
Objective-To determine the presence of antiubiquitin antibody (AUbA) in localised scleroderma and systemic sclerosis, as it is frequently found in the sera of patients with systemic lupus erythematosus (SLE) and has also been shown to have a close relationship with antihistone antibodies that have an important role in scleroderma.

Methods-Serum samples from patients with localised scleroderma $(n=48)$ and systemic sclerosis $(n=52)$ were examined by enzyme linked immunosorbent assay. Twenty samples from patients with SLE, 20 from patients with dermatomyositis, and 30 samples from healthy individuals were used as controls.

Results-AUbA was demonstrated in $44 \%$ of patients with localised scleroderma and in $42 \%$ of those with systemic sclerosis. The presence of AUbA correlated with the presence of antihistone antibodies in both localised scleroderma and systemic sclerosis.

Conclusions-AUbA is frequently present in patients with localised scleroderma and systemic sclerosis. Induction of AUbA is closely associated with that of antihistone antibodies, suggesting that ubiquitinated histone may be the target in autoimmune responses of these disorders.
\end{abstract}

(Ann Rheum Dis 1996; 55: 399-402)

The presence of autoantibodies to various heat shock proteins has been demonstrated in certain autoimmune diseases. ${ }^{1}$ Using an enzyme linked immunosorbent assay (ELISA), Muller et al demonstrated that almost $80 \%$ of patients with systemic lupus erythematosus (SLE) possessed autoantibodies to ubiquitin, a heat shock protein of 76 amino acid residues found universally in eukaryotic cells. $^{2}$ They also showed that the sera which reacted with ubiquitin contained antibodies to ubiquitinated histone $\mathrm{H} 2 \mathrm{~A} .{ }^{3}$

Scleroderma is a chronic disease of possible autoimmune origin that is classified into two types: localised scleroderma (LSc) and systemic sclerosis (SSc). LSc occurs more commonly in the paediatric population than does SSc and is further differentiated from SSc by its lack of association with Raynaud's phenomenon, acrosclerosis, and internal involvement. However, LSc and SSc have a number of features in common, such as pathological findings in the skin and the presence of autoantibodies. We have demonstrated that the major antigens for antinuclear antibodies (ANA) in LSc were nuclear histones, ${ }^{4}$ while antihistone antibodies (AHA) have been reported in $5-29 \%$ of patients with SSc. ${ }^{5}$ These findings may indicate the presence of antiubiquitin antibody (AUbA) in LSc and SSc. In this study, we used ELISA to determine the presence of AUbA in sera of patients with LSc and SSc.

\section{Patients and methods}

PATIENTS

Serum samples were obtained from 48 patients with LSc, 52 with SSc, 20 with SLE, and 20 with dermatomyositis; samples from 30 healthy individuals were used as controls. Patients and controls were all Japanese except for one patient with SLE. Patients with LSc comprised 13 patients with generalised morphea, 23 with linear scleroderma, and 12 with morphea; 13 were men and 35 were women, and their ages ranged from four to 67 years (mean 25.0 years). Patients with SSc were classified according to the system proposed by LeRoy et al: ${ }^{6} 19$ patients had limited cutaneous SSc (lcSSc) and 33 had the diffuse form (dcSSc). Of these 52, six were men and 46 were women; their ages ranged from 14 to 79 years (mean 53.0 years). Patients with SLE fulfilled the criteria of the American College of Rheumatology (formerly, The American Rheumatism Association); ${ }^{7}$ three were men and 17 were women, and their ages ranged from 18 to 43 years (mean 26.6 years). Patients with dermatomyositis were diagnosed as having definite or probable dermatomyositis according to the criteria proposed by Bohan and Peter: ${ }^{8}$ six were men and 14 were women; their ages ranged from 13 to 68 years (mean 41.6 years). Of the 30 control subjects, 10 were men and 20 were women; their ages ranged from 23 to 60 years (mean $42 \cdot 7$ years).

Clinical data were obtained at the time blood samples were drawn. Organ system involvement was defined as described by Steen et al, ${ }^{9}$ with some modifications: ${ }^{5}$ lung $=$ bibasilar fibrosis on chest radiograph; heart = pericarditis, congestive heart failure, or arrhythmias requiring treatment; oesophagus $=$ hypomotility shown by barium radiography; joint = inflammatory polyarthralgias or arthritis; kidney = malignant hypertension, rapidly progressive renal failure, or both. 
SPECIFICITY OF ANA

Indirect immunofluorescence using HEp-2 cells as the substrate, and double immunodiffusion were performed to detect ANA. Anticentromere antibody was determined by indirect immunofluorescence; antitopoisomerase I and U1RNP antibodies were determined by double immunodiffusion.

\section{ELISA FOR AUbA}

The ELISA for AUbA was performed as described previously, with some modifications. ${ }^{210}$ The purity of ubiquitin from bovine red blood cells (Sigma, St Louis, MO) was checked by sodium dodecyl sulphatepolyacrylamide gel electrophoresis (SDSPAGE) with a $15 \%$ polyacrylamide gel (fig 1 ). Ubiquitin was coated at $4 \mu \mathrm{g} / \mathrm{ml}$ in phosphate buffered saline (PBS), and serum samples (diluted 1:100) were added. All serum samples were tested in triplicate. The bound antibodies were detected with alkaline phosphatase conjugated goat antihuman IgG or IgM antibodies (Cappel, Durham, NC), using 10 $\mathrm{mg} / \mathrm{ml}$ p-nitrophenyl phosphate (Gibco BRL,

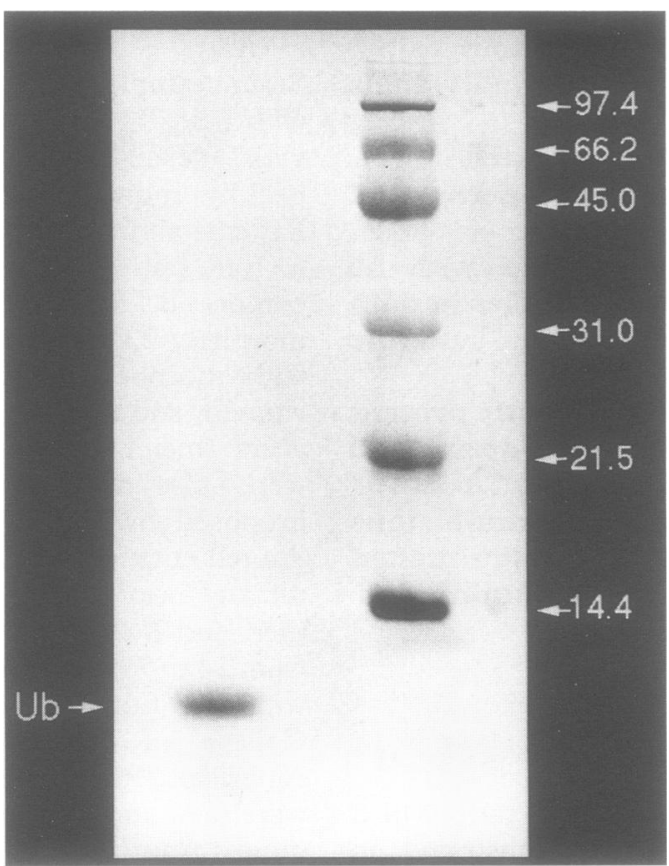

Figure 1 Purity of ubiquitin, checked on a 15\% polyacrylamide gel stained with Coomassie brilliant blue. Left lane: ubiquitin is shown as a single band at $8.0 \mathrm{kDa}$. Right lane: molecular weight markers.

Incidence of antiubiquitin antibody (AUbA) (detected by enzyme linked immunosorbent assay) in localised scleroderma and systemic sclerosis

\begin{tabular}{lrrr}
\hline Group & \multicolumn{1}{l}{$A U b A$} & & \\
\cline { 2 - 4 } & \multicolumn{1}{l}{$I g G$} & $I g M$ & $I g G$ andor IgM \\
\hline Localised scleroderma $(\mathrm{n}=48)$ & $19(40)$ & $6(13)$ & $21(44)$ \\
Generalised morphea (n=13) & $9(69)$ & $2(15)$ & $9(69)$ \\
Linear scleroderma $(\mathrm{n}=23)$ & $7(30)$ & $4(17)$ & $9(39)$ \\
Morphea (n=12) & $3(25)$ & $0(0)$ & $3(25)$ \\
Systemic sclerosis $(\mathrm{n}=52)$ & $17(33)$ & $16(31)$ & $22(42)$ \\
Limited (n=19) & $6(32)$ & $4(21)$ & $7(37)$ \\
Diffuse (n=33) & $11(33)$ & $12(36)$ & $15(45)$ \\
Systemic lupus erythematosus $(\mathrm{n}=20)$ & $11(55)$ & $7(35)$ & $14(70)$ \\
Dermatomyositis (n=20) & $2(10)$ & $0(0)$ & $2(10)$ \\
Healthy individuals $(\mathrm{n}=30)$ & $0(0)$ & $0(0)$ & $0(0)$ \\
\hline
\end{tabular}

Values represent number of patients $(\%)$.
Gaithersburg, MD) in $10 \mathrm{mmol} / \mathrm{l}$ diethanolamine and $0.5 \mathrm{mmol} / 1$ magnesium chloride (pH 9.5) as substrate. Absorbance values greater than the mean plus $3 \mathrm{SD}$ values of the normal controls were considered positive.

ELISA FOR AHA

Microtitre plates (Corning) were coated with total histones (Sigma) at $5 \mu \mathrm{g} / \mathrm{ml}$ in PBS. ELISA was performed as described previously. ${ }^{4}$ The purity of histone was checked by SDS-PAGE with a $15 \%$ polyacrylamide gel.

ELISA FOR SINGLE STRANDED DNA (sSDNA)

ANTIBODY

Wells were pretreated for one hour with $0 \cdot 1 \%$ protamine sulphate (grade X, Sigma). After rinsing with PBS, calf thymus ssDNA (Sigma) was added at $1 \mu \mathrm{g} / \mathrm{ml}$ in PBS. ELISA was then performed as described above.

STATISTICS

Fisher's exact probability test was performed to analyse frequencies. Correlations were calculated using linear regression. Values of $p$ less than 0.05 were considered significant.

\section{Results}

DISTRIBUTION OF AUbA

The table shows the frequency of AUbA positivity, as determined by ELISA. The IgG, IgM, or both isotypes of AUbA were present in 21 of 48 patients ( $44 \%$ ) with LSc, 22 of 52 patients $(42 \%)$ with SSc, and 13 of 20 patients $(65 \%)$ with SLE, but in only $10 \%$ of patients (two of 20) with dermatomyositis. None of the serum samples from healthy individuals was positive for AUbA.

CORRELATIONS OF AUbA WITH CLINICAL

FEATURES AND WITH OTHER AUTOANTIBODIES Among the three subgroups of LSc, AUbA (IgG or $\operatorname{IgM}$ isotypes) was found in $69 \%$ of those with generalised morphea-a much greater frequency than the $39 \%$ in those with linear scleroderma and $25 \%$ in those with morphea (table). There was no significant difference in linear lesion, morphea lesion, or muscle involvement.

The incidence of AUbA in patients with dcSSc $(45 \%)$ was slightly greater than that in patients with lcSSc $(37 \%)$, but this difference was not significant (table). Clinically, the presence of oesophageal involvement was significantly correlated with the presence of AUbA (18 of 22 compared with 15 of 30; $\mathrm{p}<0.05)$. There was no significant correlation between the presence of AUbA and other organ involvement including lungs, heart, joints, and kidneys.

In 48 patients with LSc, anti-ssDNA was detected in $17(35 \%)$, rheumatoid factor in 11 $(22 \%)$, and AHA in $24(50 \%)$. In 52 patients with SSc, antitopoisomerase I antibody was 

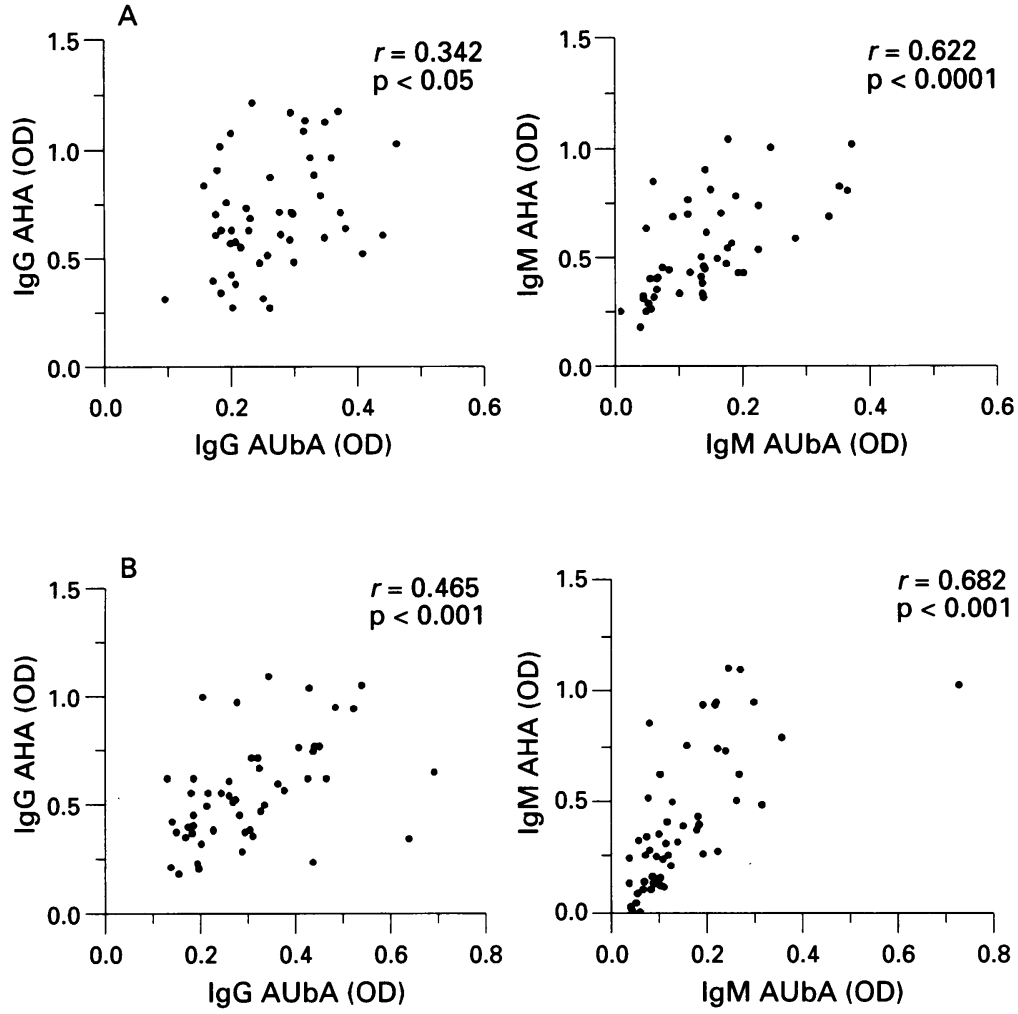

Figure 2 Relationship between amounts of antiubiquitin antibody ( $A U b A)$ and those of antihistone antibodies $(A H A)$ in patients with localised scleroderma $(A)$ and systemic sclerosis $(B) . O D=$ Optical density. who showed that AUbA is frequently present in the sera of patients with SLE, but not in other rheumatic diseases. They reported finding AUbA in $15 \%$ of 48 patients with SSc. However, in the present study we found that AUbA was frequently present not only in patients with SLE, but also in those with LSc and SSc. These differences in the incidence of AUbA positivity in SSc in these two studies may reflect differences between the populations of patients studied, including racial differences, because the methods of detecting AUbA were almost identical, and revealed similar frequencies in patients with SLE.

Another interesting finding was that the presence of AUbA was closely correlated with the presence of AHA, reflecting the findings of Muller $e t a l .^{3}$ This indicates that induction of AUbA is closely related with that of AHA, suggesting that ubiquitinated histone might be involved in the autoantigen recognition.

AHA has been shown to be a major autoantibody in $\mathrm{LSc},{ }^{4}$ and we have reported previously that AHA might be a serological indicator of the severity of pulmonary fibrosis in SSc. ${ }^{5}$ In contrast, heat shock proteins, including ubiquitin and histone $\mathrm{H} 2 \mathrm{~B}$, have been implicated in a variety of diseases, including non-viral infections and autoimmune diseases. ${ }^{114} 16$ These proteins are major immune targets in a broad spectrum of infectious diseases and, at the same time, are highly conserved in evolution, suggesting alteration of the balance between tolerance and autoimmunity. Studies on induction of autoantibodies to these proteins may therefore provide a clue to the pathogenesis of LSc and SSc. This work was supported by a research grant from the Welfare of Japan (K Takehara), and a Searle Scientific Research Fellowship (K Kikuchi). Thus the presence of AUbA was significantly associated with the presence of AHA in both LSc and SSc $(p<0.05$ and $p<0.001$, respectively). In addition, the amounts of AUbA showed significant correlation with those of AHA in both LSc and SSc (fig 2). No significant correlation was observed between the presence of AUbA and that of autoantibodies other than AHA in patients with LSc or SSc.

\section{Discussion}

Ubiquitin is a highly conserved protein that exists either freely or conjugated to a variety of nuclear, cytoplasmic, and membrane proteins. Ubiquitin conjugates are known to participate in mediating selective degradation of damaged or abnormal proteins, while histone ubiquitination is a selective, reversible postsynthetic modification that occurs mainly in actively transcribed regions of chromatin and may be involved in the mechanisms of chromatin relaxation. ${ }^{3} 1112$

Recent investigations have revealed that ubiquitin is involved in various diseases, including autoimmune diseases and neurodegenerative diseases. ${ }^{2}{ }^{13}$ Autoantibodies to ubiquitin were first identified by Muller et $a l^{2}{ }^{2}$

1 Schultz D R, Arnold P I. Heat shock (stress) proteins and autoimmunity in rheumatic disease. Semin Arthritis Rheum 1993; 22: 357-74.

2 Muller S, Briand R J, Van Regenmortel M H V. Presence of antibodies to ubiquitin during the autoimmune of antibodies to uith Proc Natl Acad Sci USA 1988; 86: 8176-80.

3 Plaue S, Muller S, Van Regenmortel M H V. A branched synthetic octapeptide of ubiquitinated histone $\mathrm{H} 2 \mathrm{~A}$ as target of autoantibodies. $\mathcal{F} \operatorname{Exp}$ Med 1989; 169: 1607-17. 4 Sato S, Ihn H, Soma Y, et al. Antihistone antibodies in
patients with localized scleroderma. Arthritis Rheum 1993;

5 Sato S, Ihn H, Kikuchi K, Takehara K. Antihistone antibodies in systemic sclerosis. Arthritis Rheum 1994; 37: 391-4.

6 LeRoy E C, Kreig T, Black C, et al. Scleroderma (systemic sclerosis): classification, subsets, and pathogenesis. $\mathcal{f}$ Rheumatol 1988; 15: 202-5.

7 Tan E M, Cohen A S, Fries J F, et al. The 1982 revised criteria for the classification of systemic lupus crythematosus. Arthritis Rheum 1982; 25: 1271-7. lupus

Bohan A, Peter J B. Polymyositis and dermatomyositis. $N$ Engl f Med 1975; 292: 344-7.

9 Steen V D, Powell D L, Medsger T A Jr. Clinical correlations and prognosis based on serum autoantibodies in patients with systemic sclerosis. Arthritis Rheum 1988; 31: 196-203.

10 Fujimoto $M$, Sato $S$, Ihn $H$, Kikuchi $K$, Tamaki $K$, Takehara K. Autoantibodies to pyruvate dehydrogenase complex in patients with systemic sclerosis: possible role of El $\alpha$ antibody as a serologic indicator for development of primary biliary cirrhosis. Arthritis Rheum 1995; 38:

11 Finley $D$, Varshavsky $A$. The ubiquitin system: functions and mechanisms. Trends Biochem Sci 1985; 10: 343-7. 
12 Davie J R, Nickel B E. The ubiquitinated histone species are enriched in histone $\mathrm{H} 1$-depleted chromatin regions. Biochem Biophys Acta 1987; 909: 183-9.

13 Manetto V G, Perry M, Tabaton P, et al. Ubiquitin is associated with abnormal cytoplasmic filaments characteristic of neurodegenerative diseases. Proc Natl Acad Sci USA 1988; 85: 4501-5.

14 Young D, Lathigra R, Hendrix R, Sweetser D, Young R A.
Stress proteins are immune targets in leprosy and tuberculosis. Proc Natl Acad Sci USA 1988; 85: 4267-70. 15 Winfield J B, Jarjour W N. Stress proteins, autoimmunity and autoimmune disease. Curr Top Microbiol Immunol 1991; 167: 161-89.

16 Fujimoto $M$, Sato S, Ihn H, Takehara K. Autoantibodies to the heat-shock protein hsp73 in localized scleroderma. Arch Dermatol Res 1995; 287: 581-5. 